\title{
Evolutionary Computation on Road Safety
}

\author{
Bruno Fernandes $^{1}(\mathbb{D})$, Henrique Vicente ${ }^{1,2}$ (D) Jorge Ribeiro $^{3}$ (D), \\ Cesar Analide ${ }^{1}\left(\mathbb{D}\right.$, and José Neves $\left.{ }^{1(\triangle)}\right)(\mathbb{D})$ \\ ${ }^{1}$ Centro ALGORITMI, University of Minho, Braga, Portugal \\ bruno.fmf.8@gmail.com, \{analide,jneves\}@di.uminho.pt \\ 2 Department of Chemistry, Évora Chemistry Centre, \\ University of Évora, Évora, Portugal \\ hvicente@uevora.pt \\ ${ }^{3}$ School of Technology and Management, ARC4DigiT - Applied Research \\ Center for Digital Transformation, Polytechnic Institute of Viana do Castelo, \\ Viana do Castelo, Portugal \\ jribeiro@estg.ipvc.pt
}

\begin{abstract}
This study examines the psychological research that focuses on road safety in Smart Cities as proposed by the Vulnerable Road Users (VRUs) sphere. It takes into account qualities such as VRUs' personal information, their habits, environmental measurements and things data. With the goal of seeing VRUs as active and proactive actors with differentiated feelings and behaviours, we are committed to integrating the social factors that characterize each $V R U$ into our social machinery. As a result, we will focus on the development of a VRU Social Machine to assess VRUs' behaviour in order to improve road safety. The formal background will be to use Logic Programming to define its architecture based on a Deep Learning approach to Knowledge Representation and Reasoning, complemented with an Evolutionary approach to Computing.
\end{abstract}

Keywords: Artificial Intelligence $\cdot$ Smart Cities $\cdot$ Vulnerable Road Users Internet of People $\cdot$ Knowledge Representation and Reasoning Evolutionary Computation 